\title{
La integración de las TIC en la clase de ELE. Panorama de una (r)evolución
}

\author{
María del Pilar Hernández Mercedes \\ Instituto Cervantes de Nápoles \\ pilarh@cervantes.es
}

Resumen: El propósito de este artículo es doble y responde a las directrices siguientes: por un lado, revisar el estado de la cuestión de la integración de las TIC en el aula de ELE y por el otro, indicar los elementos y líneas más significativos que dentro del ámbito de las TIC van a marcar la enseñanza/aprendizaje del español como lengua extranjera o L2 en un futuro inmediato desde las perspectivas tanto del estudiante como del investigador y del docente.

Palabras clave: TIC, Web 2.0, ELE, Aprendizaje, Enseñanza, Español.

\begin{abstract}
This paper has a double purpose and meets the following guidelines. First, to check the status of the issue of integration of ICT in the Spanish as a foreign language classroom. Second, to indicate the most significant lines which will shape in the near future the teaching / learning Spanish as a foreign language or L2 in the ICT from the perspectives of the students, the researchers and teachers.
\end{abstract}

Keywords: ICT, Web 2.0, SFL, Learning, Teaching, Spanish. 


\section{Introducción}

Las Tecnologías de la Información y de la Comunicación (en adelante, TIC) forman parte de forma natural desde hace algunos años de nuestro escenario vital, $y$ por lo tanto permean todos los aspectos de nuestras vidas. Esta es la realidad que conforma nuestro presente y futuro. Por lo tanto, como afirma Villatoro (2011), en una sociedad cultural y tecnológicamente compleja como la nuestra, «el profesorado debe aprender a afrontar nuevos retos y problemas educativos que no existían hace pocos años, como el saber integrar y usar pedagógicamente las tecnologías de la información y comunicación». Tanto docentes como estudiantes deben llegar a utilizar la tecnología digital con eficacia.

Partimos de la idea de que las nuevas tecnologías no constituyen un fin en sí mismo, sino que son un poderoso instrumento cuya eficacia dependerá del uso que hagamos de él. Por ese motivo, si bien no se trata de una panacea que viene a resolver todos nuestros posibles problemas, las TIC bien empleadas pueden resultar sumamente útiles. Además, con ellas, y este es su primer elemento definitorio, se pueden trascender los límites del aula y los parámetros espaciotemporales en que se han desarrollado tradicionalmente las actividades de enseñanza - aprendizaje.

Es preciso tener claro qué, por qué, para qué, cómo, cuándo y dónde. Lo que el profesor no debe perder en ningún momento de vista es la tarea final, los objetivos comunicativos que quiere alcanzar, la secuenciación de las actividades en la unidad didáctica, la gestión de los grupos, los medios de que se servirá y cómo evaluará los objetivos una vez alcanzados.

Según palabras de Olga Juan (2011: 4),

la integración de las TIC en la enseñanza de las lenguas supone un gran potencial estratégico. No son una solución de per se para todo pero aportan y concretan una serie de posibilidades tangibles a presupuestos y necesidades de las que se viene hablando desde la década de los 70 con el método comunicativo y, más recientemente a partir de la publicación del MCER.

En este momento, el uso de TIC ya no constituye tema de debate pero aún queda mucho camino por recorrer. Es necesario, por tanto, hacer acopio del mayor número de experiencias posible, en los contextos más variados, y analizar los resultados obtenidos para poder hacer nuevas propuestas o consolidar algunas de las ya llevadas al aula. Por otro lado, hay que facilitar al máximo la integración de aspectos relacionados con las TIC, su buen uso y explotación, en la formación del profesorado. 


\section{La Web social}

Durante mucho tiempo hemos considerado la web como una fuente inagotable de input, una especie de gran biblioteca repleta de contenido a la que todos los usuarios de Internet podíamos tener acceso como receptores de diferentes tipos de contenido. Los creadores de todos los materiales que encontrábamos allí eran especialistas, profesionales de la informática, y eso confería a la Web 1.0 el carácter vertical que la definía. De forma oficial, sabemos que ese periodo se dio por concluido en 2004 cuando Tim O'Reilly lanzó la marca Web 2.0, conocida también como Web social o Web colaborativa; pero sería erróneo considerar que esta nace en ese preciso momento; se trata más bien de un punto de inflexión a partir del que los usuarios empiezan a tomar conciencia de que se está viviendo un cambio. Entre el primer estadio de la Web y la llamada Web social hay una continuidad natural caracterizada por la existencia de pequeños y grandes saltos en su evolución. El momento presente, que podríamos considerar de consolidación y generalización de los servicios colaborativos, no es más que un punto en la línea vital de la digitalidad.

En esta generación la Web sigue estando repleta de contenido, esto no ha cambiado, pero ya no es necesario poseer conocimientos especiales para crear nuevo contenido y participar. Como ya hemos dicho, el poder ha pasado del especialista al usuario de a pie; el estatismo ha cedido su lugar a la participación. Esta idea va mucho más allá de la mera facilidad de uso de la Web con que efectivamente nos encontramos: se ha producido un auténtico movimiento de democratización de la red. Los usuarios que en un principio se limitaban a leer la Web ahora participan en ella, pasando de ser consumidores a ser prosumidores (productores + consumidores) de la información con la posibilidad de servirse de innumerables utilidades y herramientas no sólo de fácil manejo, sino además, muchas de ellas completamente gratuitas. Estamos, pues, ante la Web enfocada a ese prosumidor del que hablábamos, cuyo centro es ocupado por diferentes sistemas de distribución de información y opinión, verdaderos protagonistas de esta revolución; gracias a los que se produce el movimiento reticular de la información.

Los principios básicos son crear, compartir y participar. La creación se comparte con otros para aprender con ellos, a la vez que se participa. Esto lleva a un aprendizaje cooperativo y a la creación social del conocimiento. Dentro de la Web 2.0, aunque lo llamativo de muchas de sus herramientas y aplicaciones pueda llevar fácilmente a pensar lo contrario, en realidad, es el contenido lo que se valora $y$, en especial, la manera en que este se distribuye. 
Lo que define de forma más exacta todo este fenómeno es el término «conversación» (no sólo entre personas sino también entre medios): se ha establecido una relación reticular entre usuarios que, al mismo tiempo, son nodos distribuidores, consumidores y generadores. Por eso la Web 2.0 se centra en el usuario y, sobre todo, en la conversación entre esos nodos creando una vastísima interacción digital.

La red social no es sólo un conjunto de formatos o aplicaciones, va más allá de las meras herramientas digitales. Como dice Christian Van Der Henst, la Web 2.0 no es sólo una tecnología, es una actitud y, por lo tanto, implica un cambio en la forma de ver las cosas.

Por su parte, «en la didáctica de lenguas extranjeras en Europa se está viviendo un cambio de perspectiva, favorecido por el posicionamiento del MCER hacia una perspectiva orientada a la acción en la que el carácter instrumental de la lengua adquiere una especial relevancia: los hablantes como agentes sociales utilizan la lengua para actuar y resolver con ella tareas de la vida cotidiana en un entorno social concreto y en cooperación y negociación con otros usuarios de la lengua, para conseguir un objetivo común. Más allá del uso comunicativo de la lengua, se enfatiza el carácter accional de esta» (Herrera/Conejo 2009: 2).

El uso de la lengua como el de la Web 2.0 son fenómenos sociales que se basan en la interacción entre los individuos, y las identidades lingüística y digital no pueden construirse de forma aislada: con la Web 2.0 estamos ante un entorno social tecnológico formado por individuos - usuarios de la lengua y de la tecnología Web- que interactúan entre sí para resolver tareas comunicativas digitales.

\subsection{Clasificación}

En estas páginas no nos vamos a ocupar de todas las herramientas y utilidades de la Web 2.0, ni siquiera de las más actuales, sino de aquellas especialmente significativas en el ámbito de la enseñanza y aprendizaje de ELE por ser las que con más estudios y análisis de experiencias cuentan hasta el momento. Se trata de materiales, todos ellos, en línea a disposición de la comunidad de docentes (bien como publicaciones, bien como documentos de diversa índole en la red). De cada una de las aplicaciones expuestas indicaremos posibles explotaciones en el aula ELE y aspectos que por sus características pueden mejorar los procesos de aprendizaje. Obviamente, todas ellas suponen también el desarrollo de la competencia digital de los alumnos.

El objetivo de este apartado es que los profesores se familiaricen con herramientas clásicas de la Web 2.0 y, sobre todo, con los posibles usos de tales he- 
rramientas en el aula, a fin de propiciar la reflexión y el sentido crítico sobre su aplicación en la enseñanza de ELE.

En una primera fase de la Web social, nos encontramos con tres formatos básicos: blogs, wikis y podcast. Estos dieron paso a los grandes repositorios de imágenes: Youtube para vídeo y Flickr para fotografías, sobre todo. El tercer momento corresponde a las redes sociales como Facebook o Twitter (microblogging), por ejemplo. En la clasificación hemos optado por la propuesta de Herrera y Conejo (2009: 5), ya que refleja la manera en que estas aplicaciones permiten a los usuarios hacer circular la información. Así pues, nos encontramos con aplicaciones verticales, horizontales y reticulares, que se vienen a identificar con esas tres fases de los servicios colaborativos de las que acabamos de hacer alusión.

\subsubsection{Blog}

Definido como «La gran conversación» (Orihuela 2005), se trata de una página web organizada cronológicamente, que admite comentarios y suscripciones y que lleva una línea editorial más o menos definida. Básicamente, nos hallamos ante un espacio personal de escritura en Internet.

Los blogs se organizan mediante categorías y los define su carácter multimedia (imágenes, audio, vídeo). Entre los docentes interesados en TIC hay preocupación porque se resguarde y mantenga la calidad de los llamados Edublogs (blogs educativos que presentan diversos niveles de uso).

Dentro de este ámbito, en cuanto a los blogs en el mundo ELE, podemos destacar tres amplias categorías:

Blogs del profesor

En los que el docente puede compartir material de los contenidos que desarrolla, incluir sugerencias de aprendizaje y realizar reflexiones sobre la didáctica de ELE.

Blogs de clase

Constituyen un lugar de encuentro de los alumnos para el desarrollo de proyectos comunes y/o colaborativos. Suponen un buen momento para la activación de la participación y el debate.

Blogs del alumno

Permiten el seguimiento del proceso de aprendizaje por parte del profesor $y$ del alumno. Pueden ser empleados como bitácoras (diarios personales de aprendizaje) o también como portafolios donde quede constancia de la progresión y logros del aprendiente.

Las posibilidades pedagógicas que presentan los blog son muchas. El profesor entre otras cosas puede proponer la realización de tareas, incluir trabajos que los 
alumnos deben realizar, así como lanzar temas que quiera desarrollar, o también llevar a cabo debates. Es posible incluir apuntes de las clases o aclaraciones, enlaces de interés para ampliar la formación e incluso orientaciones de estudio.

Facilitan una audiencia real y un contexto de desinhibición, mejorando la interacción entre los participantes.

Con ellos, se pone énfasis en los procesos y se producen situaciones reales de comunicación. Además de permitir revisiones compartidas, que pueden resultar de gran utilidad en ELE, ofrecen nuevas formas de producción escrita y creatividad con diferentes niveles de redacción y escritura.

Es muy difícil hacer una selección de blogs, dada la ingente cantidad de experiencias existentes en este campo. Ofrecemos a continuación algunos ejemplos interesantes y significativos dentro del ámbito ELE:

$<$ http://todoele.org/todoele20/blog > - Blog de una comunidad de profesores $<$ http://todoelecomunidad.ning.com/profiles/blog/list $>$ - Entradas de blogs de profesores

$<$ http://jramonele.blogspot.com.es $>$ - Blog de profesor

$<$ http://sites,google.com/site/profemunday/home $>$ - Blog profesor

$<$ http://ler-ele.blogspot.it/> - recursos

$<$ http://www.profeland.com $>/$ - recursos

$<$ http://www.profesorenapuros.es/ > - recursos

$<$ http://www.davidal.es/lanavaja/ > - TIC

$<$ http://www.nodosele.com/blog/ > - TIC

$<$ http://espanolporloscuernos.blogspot.it/ > - ELE y DELE visto por alumnos $<$ http://www.eldigoras.com/eldyele/17blogs.htm > - Listado de blogs $<$ http // www.educacontic.es $>$ (no es específico de ELE, pero es fundamental en este ámbito).

\subsubsection{Wiki}

Se trata de un sitio Web, cuyas páginas pueden ser escritas de forma colaborativa y ser modificadas por cualquier participante. Es un editor de páginas sencillo con el que, además, es posible enlazar páginas, incluir imágenes y archivos de audio y vídeo, etc. El término Wiki (que viene del hawaiano «wiki wiki» y significa rápido) con el que es conocida esta herramienta, da la idea de la rapidez y facilidad de creación y gestión. En la actualidad el wiki más conocido y difundido es <http:// wikipedia.org>, enciclopedia libre, disponible en varios idiomas y accesible a todos los usuarios. 
El funcionamiento instrumental de esta herramienta podría quedar resumido en estas tres acciones:

\section{$\mathrm{EDITAR} \rightarrow \mathrm{ESCRIBIR} \rightarrow$ GRABAR}

Para comprender perfectamente qué es un Wiki y cuál es la filosofía que lo anima recomendamos el vídeo <http://es.youtube.com/watch?v=jIgk8v74Izg > (a pesar del tiempo transcurrido desde su creación, sigue siendo la forma más didáctica de aproximarnos a esta realidad).

El uso de esta herramienta se está revelando muy positivo puesto que favorece el modelo constructivista de aprendizaje y va más allá de la práctica de la expresión escrita. Sirve sobre todo para fomentar el aprendizaje colaborativo. Además, al romperse la jerarquización, el alumno se siente protagonista de su propio proceso de aprendizaje. Todo ello hace que el factor motivación sea muy alto.

Una de las características más importantes y diferenciadoras del Wiki con respecto a otras herramientas es que permite tener un historial de cambios.

En el aula de ELE nos pueden ser útiles para:

- Crear apuntes colectivos.

+ Crear trabajos en grupo.

- Crear el portafolio del alumno o de la clase.

- Coordinar la distribución de tareas para cualquier tipo de trabajo colaborativo.

+ Revisar el trabajo de un alumno o de un grupo.

- Coordinar trabajos con alumnos de otros centros.

- Trabajar con la corrección de errores.

+ Etc.

Algunas experiencias en este campo:

$<$ http://todoele.wikispaces.com/> - Herramienta de desarrollo profesional $<$ http://universoele.wikispaces.com $>$ - Colaboración entre profesores y formación

<http://es.wiktionary.org/wiki/Wikcionario:Portada> - Editar glosarios $<$ http://aprenderescribiendo193.pbworks.com > Expresión e interacción escrita

$<$ http://elepedia.org > - Enciclopedia de ELE

$<$ http://quevivaele.wikispaces.com/> - Unidad didáctica

$<$ http://ele10.wikispaces.com/ > - Selección de recursos

$<$ http://palabrasele1.wikispaces.com/> - WebQuest

$<$ http://eletic.wikispaces.com/ > - Curso de formación 
Tras analizar las características y posibilidades de blogs y wikis lo natural es plantearse las similitudes y las diferencias entre ellos. Partiendo de la base de que su funcionalidad es diferente, hay que tener en cuenta que la preferencia por uno u otro es, para muchos docentes, una cuestión de empatía con el medio.

\begin{tabular}{|l|l|}
\hline Wiki & Blog \\
\hline Es colaborativo & Es personal \\
\hline $\begin{array}{l}\text { Se puede cambiar siempre que se } \\
\text { quiera. }\end{array}$ & $\begin{array}{l}\text { El texto es estático. Una vez publicado, } \\
\text { no cambia. }\end{array}$ \\
\hline Se estructura en páginas. & $\begin{array}{l}\text { Tiende a presentarse como un largo per- } \\
\text { gamino (pero se puede estructurar en } \\
\text { categorías) }\end{array}$ \\
\hline Es hipertextual. & Enlaces externos \\
\hline Es atemporal & Es cronológico \\
\hline Presenta modo de edición & Presenta modo discusión \\
\hline
\end{tabular}

\subsubsection{Podcast}

Se trata generalmente de archivos de audio que están disponibles en la red (por lo tanto se pueden escuchar y descargar cuando se desee y las veces que se quiera) y que cuentan con servicios de suscripción (<http://es.wikipedia. org/wiki/Podcasting $>$ ). Recomendamos aquí también un vídeo sumamente didáctico para comprender esta herramienta: <http://www.youtube.com/ watch?v=3GMIZcaw55s $\& \mathrm{NR}=1>$.

En la clase de ELE, como detalla J. Tallei (2010), sus posibilidades son muchas. En este caso, dado que es más difícil encontrarlos en la Web, aportamos también una serie de direcciones útiles.

- Obtener muestras de entrevistas y hacer luego simulaciones con los alumnos. <http://www.cadenaser.com/podcast/> o <http://www.radiocervantes.es/podcast $>$

- Practicar la pronunciación (por ejemplo: lectura de un artículo o de un poema). <http://spanish-podcast.com/es/category/podcast >

- Grabar producciones orales de los alumnos (reflexiones, experiencias, opiniones, viajes, recetas, consejos...) de manera puedan ser compartidas con los compañeros. $<$ http://portfoliodespanol.wordpress.com $>$

- Para que los alumnos se familiaricen con las variantes del español y reflexionen sobre ellas. <http://www.audio-lingua.eu >

- Realizar actividades comunicativas de la lengua (comprensión y expresión oral, expresión escrita...) y reforzar contenidos lingüísticos. $<$ http://www.ticele.es/category/podcast/podcast-a1> 
$<$ http://www.dpili.com>

$<$ http://www.audiria.com/capitulos-detalle.php?id=604>

- Realizar un proyecto de radio.

$<$ http://radiodigital.wikispaces,com >

- Finalizado a la formación, al desarrollo profesional y la colaboración entre profesores. $<$ http://eledelengua.com $>$

- Audiolibros: Se pueden bajar a cualquier soporte de lectura audio. Además de su evidente utilidad para el alumno en el desarrollo de estrategias de escucha y comprensión auditiva, los profesores podemos utilizarlos para diseñar secuencias didácticas según objetivos de lengua determinados, ofrecerlos como ejercicios para practicar la pronunciación o también para enseñar cultura.

$<$ http://www.leerescuchando.net >

$<$ http://audiolibros.podomatic,com $>$

Por otro lado, nos parece muy interesante reseñar aquí, por lo articulado del proyecto y los objetivos fijados, En sintonía con el español (<http://cvc.cervantes. es/ensenanza/ese/>), del Centro Virtual Cervantes (Instituto Cervantes) que vio la luz en septiembre de 2011 y que ofrece cada mes un podcast descargable y actividades de aprendizaje interactivas (a partir del nivel A2). Los objetivos son:

- Trabajar sobre un asunto formal que genera o puede generar errores en la producción de los alumnos y ofrecer herramientas de reflexión que favorezcan la concienciación y permitan tanto la prevención como el tratamiento de dichos errores.

- Proporcionar actividades de práctica de la escucha que permiten el desarrollo de la autonomía de aprendizaje.

- Estimular la interculturalidad huyendo de folklorismos.

- Garantizar el carácter colaborativo, de construcción colectiva, gracias a un blog (ese.blogs.cervantes.es) y a una cuenta en Twitter con los que se pretende que los estudiantes y los profesores sean quienes construyen el proyecto, sugiriendo temas y generando debates para promover un intercambio real, en el espíritu de la Web social.

Tras este abanico de posibilidades de trabajo con podcast en ELE, que como hemos visto constituye tanto material de input como de output, pasamos ahora a enumerar las características, que con un correcto uso de esta herramienta, pueden revertir positivamente en el aula: 
- Contribuir al desarrollo de la comprensión auditiva de los estudiantes.

- Ayudar a trabajar con la pronunciación y la prosodia en el aula.

+ Trabajar con material auténtico.

- Desarrollar el aprendizaje autónomo y la interacción entre los alumnos.

Cerramos el presente apartado indicando una página donde se explican los pasos para la creación de podcast: <http://www.podcastes.org/index.php/ComoHacerPodcast>.

\subsubsection{Redes sociales}

Hace algunos años se empieza a hablar en los encuentros de profesores de ELE de experiencias de aplicación de redes sociales en la enseñanza / aprendizaje de ELE. En ellas se destaca su valor como herramientas de comunicación que permiten al profesor entrar en la realidad cotidiana de muchos de nuestros estudiantes y son consideradas, además, como ocasiones para que los alumnos piensen en español en momentos en que en otra circunstancia no lo harían. En tales experiencias se plantea en general la realización de tareas breves y poco articuladas en las que se pone de relieve el papel del profesor como elemento motivador y guía y se subraya el valor de la ruptura de las limitaciones espacio-temporales del aula. Podemos destacar también que se ha demostrado una opción válida, sobre todo, con alumnos que ya usaban estas aplicaciones de forma habitual en su vida cotidiana.

\section{a. Facebook}

«El uso de las nuevas tecnologías en el aula de idiomas, y en concreto, de Facebook, favorece las relaciones personales entre estudiantes y educadores, y aumenta la credibilidad de los docentes ante los ojos de los alumnos» (Pilar Concheiro: <http://www.20minutos.es/noticia/900177/0/>). Esta afirmación, cuya segunda parte creó en nosotros un cierto estupor en un primer momento, se ha visto confirmada por los testimonios a los que hemos tenido acceso a lo largo de estos últimos meses, tanto a nivel escolar como a nivel universitario; a nivel formal y no formal. En realidad, sobre el uso de redes sociales en el aula de ELE ya disponemos de algunas experiencias y reflexiones, pero es precisamente en este momento cuando creemos que se puede hablar de auténtico despegue.

El uso de Facebook en ELE, con estudiantes habituados a este medio, supone llevar la clase más allá del aula rompiendo efectivamente las barreras espacio temporales y abriéndola a un entorno de inmersión. Los alumnos se familiarizan con la lengua meta en condiciones reales y de forma más relajada que en el aula, pues 
se hallan en un entorno muy familiar e informal para ellos y aprenden a comunicar con propósitos reales, interactuando en la lengua meta. Es una forma de llevar el mundo a los cursos, creando comunidades que tienen también la posibilidad de entrar en contacto con otros grupos o individuos, no nativos y nativos, con la ventaja de contar siempre con materiales actualizados. La motivación, el aprendizaje significativo, la interacción, etc, están garantizadas. Se da, además, visibilidad a las iniciativas y trabajos de los estudiantes. Por otro lado, las relaciones entre estudiantes y docentes se ven favorecidas, pues se comparte con los alumnos el conocimiento de la red.

Por los testimonios recogidos, llegamos a la conclusión de que una utilización pertinente y adecuada de Facebook (u otras redes similares, si bien la elegida es la más significativa por su facilidad de acceso y difusión) puede revelarse muy positiva en el aprendizaje (significativo, autónomo, colaborativo, etc.) de nuestros alumnos. Obviamente, pueden presentarse inconvenientes y estos generalmente están relacionados principalmente con dos ámbitos:

- La privacidad: con cuestiones que se pueden plantear a distintos niveles (padres que no permiten que sus hijos estén en Facebook o que no desean que se comuniquen con los docentes por este medio, adultos que no quieren formar parte de ninguna red, etc.). Algunos de los inconvenientes pueden evitarse con la apertura de perfiles y grupos privados y exclusivos.

- La formación: un uso adecuado exige docentes preparados. No basta, claro está, con conocer la herramienta (esta afirmación, obviamente, es válida para la inclusión de cualquier herramienta y soporte en el aula). Por otro lado, este es uno de los campos en los que la recogida y análisis de experiencias y reflexiones aún tiene mucho camino por recorrer.

\section{b. Twitter}

Twitter un servicio gratuito de microblogging, que hace las veces de red social. Permite a sus usuarios enviar micro-entradas de texto, denominadas «tweets», de una longitud máxima de 140 caracteres. El envío de estos mensajes se puede realizar tanto a través del sitio Web de Twitter, como vía SMS desde un teléfono móvil, desde programas de mensajería instantánea, o desde aplicaciones de terceros (por ejemplo, Facebook). Estas actualizaciones se muestran en la página de perfil del usuario, y son también enviadas de forma inmediata a otros usuarios que han elegido la opción de recibirlas. A estos usuarios se les puede restringir el envío de estos mensajes sólo a miembros de su círculo de amigos o permitir su acceso a todos los usuarios, que es la opción por defecto. 
Pasemos revista ahora a algunos de sus posibles usos en el aula: ${ }^{1}$

- El profesor lanza el inicio de una frase. Cada alumno la completa de forma diferente. En niveles superiores se pueden proponer concursos con refranes o frases hechas. En este caso se hacen tweets hasta que completan correctamente la frase o indican su significado.

- Se pide a los alumnos que lean una fábula (<http://edyd.com $>$ ) y escriban la moraleja.

- Se les pide que resuman un escrito en máximo 140 caracteres.

- Se les invita a expresar las sensaciones que les produce una obra de arte o a que hipoticen por qué el autor la hizo de esa manera.

- Los alumnos escriben en una frase una noticia del día.

- Se hace un «tweet» con una palabra y se pide la definición o que aporten antónimos o sinónimos o que escriban frases que la contengan.

- Se hace un «tweet» con varias palabras: cada uno crea una frase que las contenga.

- Se hace un «tweet» con el inicio de una historia y la continúan los alumnos.

- Los alumnos dan, de forma breve y concisa, su opinión sobre un tema.

- Se lanza un acertijo o una adivinanza.

- Se lanza una tradición/fiesta y los alumnos ofrecen datos sobre ella. En el aula se analiza todo lo aportado.

- Se puede usar simplemente para dar avisos de clase.

Como experiencias concretas de uso de esta herramienta en ELE vamos a destacar dos:

1. En el Instituto Cervantes de Tokio se ha empezado, hace algún tiempo, a experimentar de forma bastante exitosa con la herramienta Twitter:

- Para practicar la competencia gramatical: se publican en la cuenta del Instituto frases con un error. Los alumnos participan proponiendo la corrección.

- Para practicar la competencia pragmática: se publican frases aisladas y los alumnos participan proponiendo un contexto.

Los ejercicios se publican semanalmente y están clasificados por niveles.

2. Hemos recogido varias experiencias con estudiantes norteamericanos (1820 años), de un centro de enseñanza de ELE, en inmersión total (un mes) en Barcelona. Todos conocían y usaban habitualmente la herramienta propuesta. El profesor no les planteaba tareas concretas con Twitter pero establecía un número

1. Encontramos algunas de estas sugerencias y otras reflexiones sobre el uso de Twitter en el blog de Tecnele: <http://tecnele.wordpress.com/2010/07/27/twitter-en-la-ensenanza-de-ele/>. 
de tweets mínimo que debían producir en un periodo concreto. Los estudiantes tenían que escribir sobre sus actividades y experiencias de su vida en España eligiendo ellos en total autonomía el momento y el contenido de su comentario. La reflexión realizada por varios docentes sobre este uso (presentada en dos encuentros didácticos diferentes) nos lleva a pensar en las posibles ventajas de la introducción de tales herramientas con públicos y en contextos concretos.

\subsubsection{Plataformas}

No queremos concluir este apartado sin una breve alusión a las plataformas virtuales pues, actualmente, lo habitual en una carrera docente/discente es entrar en contacto con esta realidad. Las posibilidades son muchas: hay numerosos cursos de formación de profesores alojados en ellas; hay docentes que deben trabajar con ellas por ser el medio elegido por la institución para la que trabajan; otros las eligen como medio de trabajo, independientemente de los dictámenes del centro de trabajo; los alumnos de muchos de los cursos de postgrado, master y/o doctorados existentes en el mercado desarrollan parte o toda su actividad en ellas; etc. El término plataforma virtual hace referencia a la tecnología utilizada para la creación y desarrollo de cursos o módulos didácticos en la Web. Como tal, y siguiendo la definición dada por la Wikipedia (<http://es.wikipedia.org/wiki/ Plataformas_virtuales_did\%C3\%A1cticas $>$ ), son una herramienta que introduce al docente en la creación de cursos y talleres, de forma sencilla y rápida, aprovechando el volumen y trascendencia de los contenidos académicos y de investigación que se tienen en un tiempo y ámbito determinado. Se caracterizan por ser medios que presentan y modifican la información de manera dinámica formando un proceso de modificaciones sucesivas y por tener la capacidad de integrar diferentes medios simbólicos. De las muchas que existen en el mercado vamos a ocuparnos de dos. La primera, por ser la más conocida popular y, la segunda, por ser la plataforma de una institución dedicada al español y su cultura: el Instituto Cervantes.

a. Moodle

Modular Object-Oriented Dynamic Learning Environment (Entorno de aprendizaje dinámico y modular orientado a objetos) empleado en más de 100 países y traducido a más de 50 idiomas.

<http://Moodle.org/> es el principal centro de difusión (descargas y documentación). Sin entrar en detalles, destacaremos ahora sus principales características: Se trata de un software libre con coste nulo de instalación y empleo (esto 
constituye un gran atractivo) y que puede modificar y alterar para adaptar su funcionamiento a cada necesidad específica.

Se presenta como un andamiaje al que subir los elementos que necesitemos para nuestros cursos y alumnos. Presenta tres herramientas de comunicación (foro, chat y correo electrónico) y permite crear Webquest, wiki y blog y subir actividades utilizando el programa JCLIC u otros programas de archivos en línea.

Se puede crear también una comunidad de profesores y/o alumnos para intercambiar opiniones mediante el foro. Presenta otras herramientas como Calendario / Tablón de noticias, etc.

\section{b. AVE (Aula Virtual de Español)}

El AVE es un entorno virtual de aprendizaje diseñado exclusivamente para la enseñanza del español por el Instituto Cervantes. En la actualidad se hayan alojados en él 16 cursos de español general (del nivel A1.1 al nivel C1.4), tres cursos para niños y adolescentes (Hola Amigos 1, 2 y 3), dos cursos de preparación al DELE (Diploma de Español como Lengua extranjera, niveles B1 y B2) y un curso de formación de tutores AVE. La plataforma, de acceso restringido, es empleada, además, en cursos específicos de la oferta formativa para profesores del Instituto Cervantes.

El AVE utiliza los recursos de Internet de forma pedagógica y pone a disposición del alumno cursos novedosos y fácilmente accesibles. El alumno tiene libertad para elegir el momento, el ritmo y el lugar de estudio y de aprendizaje. El AVE pone a disposición de sus alumnos y tutores tres escenarios de comunicación: chat, foros y correo electrónico. La disponibilidad de texto, sonido e imágenes en los productos multimedia permite ofrecer a los estudiantes muestras de lengua en su contexto real, atractivas presentaciones y ejercicios interactivos con los que practicar de forma autónoma los contenidos.

El alumno tiene a su disposición:

+ Materiales didácticos de naturaleza multimedia e interactivał vídeo, grabadora, audiciones, juegos...

- Herramientas de comunicación: blogs, wikis, correo electrónico para el envío de texto, sonido e imágenes, chat, foros, audioconferencia...

- Un tutor personal (en los cursos a distancia con tutor - ADCT-) que lo orienta, lo aconseja, prepara actividades de refuerzo o motivación y lleva a cabo la evaluación de su trabajo.

+ Un grupo de aprendizaje colaborativo a distancia (en los cursos ADCT). 
- Un sistema de seguimiento automático que recoge los datos de las actividades realizadas y permite que el alumno disponga siempre que lo desee de información sobre sus progresos ${ }^{2}$.

El AVE, caracterizado por su flexibilidad y por estar en constante actualización (incorporando las novedades tecnológicas que surgen de manera incesante en el mercado, los cambios en la enseñanza en línea y en el mundo que se representa en las actividades), presenta un diseño en módulos independientes y una estructura fragmentada, ideada inicialmente para un entorno autónomo de aprendizaje. Al tratarse de un sistema integrado (combinación de MDM, herramientas de comunicación y de gestión de la actividad docente) de enorme flexibilidad, podemos hablar de distintas modalidades de uso y de explotación: en cursos a distancia, en cursos semi-presenciales, como base de cursos presenciales, como recurso de aprendizaje, etc.

Invitamos a visitar el portal dedicado a la presentación y difusión de esta plataforma en: http://ave.cervantes.es. Por otro lado, se puede acceder de forma libre y gratuita a numerosas actividades de los cursos generales de español en el AVE, debidamente clasificados por niveles, en la AVETECA (<http://cvc. cervantes.es/ensenanza/actividades_ave/aveteca.htm >).

\section{Competencia digital docente}

Si bien lleva ya unas décadas en el panorama internacional, se trata de una de las competencias menos conocidas; condición esta que perderá rápidamente, como veremos más adelante, dado el interés que está actualmente despertando en el ámbito formativo. El Plan Curricular del Instituto Cervantes (2006) contempla esta competencia y la define del siguiente modo: «la Competencia Digital implica el uso confiado y crítico de los medios electrónicos para el trabajo, ocio y comunicación. Las destrezas de TIC comprenden el uso de tecnologías multimedia para recuperar, evaluar, almacenar, producir, presentar e intercambiar información, comunicarse y participar en redes sociales a través de Internet».

Actualmente, encontramos que en la descripción de los perfiles de profesores de idiomas las TIC forman parte de los conocimientos y habilidades que éstos deben poseer. Es necesario apelarse a ella, como sostiene Olga Juan (2010), para apoyar un cambio de actitud que favorezca la experimentación con los servicios y herramientas de las TIC. Por lo tanto, y de manera ineludible, la competencia digital es una más de las competencias generales de un docente.

¿Cómo podemos definir adecuadamente esta competencia? Se trata del conjunto de conocimientos, habilidades y actitudes para tratar las tecnologías de la

2. Fuente: <http://www.cervantes.es/lengua_y_ensenanza/aprender_espanol/cursos_espanol_internet.htm >. 
información y la comunicación, y la capacidad de integrar todo ello en su actuación docente para planificar la enseñanza, desarrollarla y evaluarla.

Nociones como competencia informacional, alfabetización múltiple, ciudadanía digital, competencia tecnológica, competencia cognitiva genérica, comunicación y colaboración encuentran su espacio en la definición de la competencia digital en general, en la docente en particular y en los diferentes estadios que se pueden alcanzar3.

A la hora de hablar de $\mathrm{CDD}$, son cinco las fases o dimensiones que se vienen considerando:

1. Acceso. Aprender el uso de la tecnología

2. Adopción. Usar la tecnología como soporte de las formas tradicionales de aprender.

3. AdAPTACión. Integrar las TIC en prácticas tradicionales centradas, por lo general, en la producción de los estudiantes.

4. Apropiación. Estamos ante una naturalización de las tecnologías y ante un tipo de trabajo cooperativo, interdisciplinar, basado en proyectos de aprendizaje, usando la tecnología cuando es necesaria. Es la fase en la que los profesores ya tienen incorporada la tecnología en el planteamiento de clases y comienzan a experimentar nuevas maneras de trabajar didácticamente utilizando la tecnología.

5. InNovación. Utilizar la tecnología de una manera que antes no la había usado nadie. Estamos en la fase en que los profesores innovan, crean cosas nuevas.

Una adecuada reflexión sobre nuestra labor docente nos permitirá saber y tomar conciencia del estadio en que nos encontramos para poder actuar en consecuencia. Esto no significa que todos debamos llegar al quinto estadio sino que todos seamos conscientes de dónde hemos llegado y qué tenemos por delante.

Son varios los documentos a los que los docentes podemos acudir para realizar una correcta valoración de nuestra CDD; pero antes de continuar, dedicaremos, por su importancia, unas líneas a los Estándares de competencias TIC para docentes (UNESCO 2008) en cuya introducción podemos leer como objetivos generales:

- Mejorar la práctica de los docentes en todas las áreas de su desempeño profesional, combinando las competencias en TIC con innovaciones en la pedagogía, el plan de estudios (currículo) y la organización escolar.

- Lograr que los docentes utilicen las competencias en TIC y recursos para mejorar sus estrategias de enseñanza, cooperar con sus colegas y en última ins-

3. Se aconseja el vídeo de Jordi Adell: <www.youtube.com/watch?v=tjC1LOC0r1g>. 
tancia poder convertirse en líderes de la innovación dentro de sus respectivas instituciones.

+ El proyecto pretende ayudar a mejorar la calidad del sistema educativo a fin de que contribuya al desarrollo económico y social de un país.

Tras esta ineludible referencia cuyo contenido completo invitamos a consultar en la página de Eduteka ${ }^{4}$, pasamos ahora a comentar una serie de documentos de referencia a los que puede acudir el profesor para conocer su grado de competencia digital y para saber qué habilidades tiene que desarrollar para mejorarla. Se trata de cinco trabajos en los que poder analizar la CDD en la descripción de los perfiles de profesores de idiomas:

\subsection{European Profile for Language Teaching Education. A Frame of Reference. $2004^{5}$}

Este documento, además de subrayar la utilidad de las TIC para la planificación personal, la organización y descubrimiento de recursos (es decir, como herramienta profesional que facilita la comunicación y el intercambio de información), se centra entre otras cosas en la formación del profesor en TIC para su uso pedagógico. Dicha formación implicaría:

- Integrar las TIC dentro y fuera de clase, hacer conscientes a los profesores de que su uso forma parte de un proceso continuo y de que ofrece herramientas didácticas muy valiosas.

- Dirigir los resultados a fomentar la autonomía de aprendizaje.

- Realizar formación orientada a saber cuándo utilizar las TIC e integrarlas dentro de los planes de clase.

El uso de las TIC se vincularía, pues, al desarrollo de las habilidades comunicativas, a la localización de recursos y documentación y al uso de procesadores de texto.

\subsection{EAQUALS: A Profiling Grid for Language Teachers (V 0.30). 2007-2009. Brian North, Galya Mateva, Richard Rossner 2007-20096}

Eaquals es una asociación internacional formada por diversas instituciones y organizaciones relacionadas con la enseñanza de la lengua. El objetivo de este perfil

4. <http://www.eduteka.org/EstandaresDocentesUnesco.www.eduteka.org php $>$.

5. <http://www.lang.soton.ac.uk/profile/report/MainReport.pdf>.

6. $<$ http://www.eaquals.org/pages/?p=7104>. 
del profesor de idiomas es promover y garantizar una alta calidad en la enseñanza de la lengua. Se describe el recorrido profesional de los docentes con una parrilla, en la que se encuentran descriptores para tres niveles de competencia de los profesores de idiomas (básico, independiente y competente), estructurada en cuatro áreas de competencias:

+ Lengua

+ Cualificaciones y experiencia

+ Competencias básicas:

- Metodología

- Interacción con el alumnado y monitorización

- Evaluación

+ Competencias complementarias:

- Desarrollo profesional

- Recursos digitales

\subsection{EPSTL: European Portfolio of Student Teachers of Languages, 2007}

Versión española, PEFPI: Portafolio europeo de futuros profesores de idiomas. $2010 .^{7}$ Se trata de un documento elaborado por el CELM (Centro Europeo de Lenguas Modernas del Consejo de Europa), concebido para que los profesores en formación reflexionen sobre los conocimientos didácticos que necesitan para enseñar. Ayuda a evaluar las competencias didácticas y permite seguir de cerca el progreso así como registrar las experiencias como profesor en el transcurso de la formación. ${ }^{8}$

Consta de las siguientes secciones:

- Una declaración personal, que invita a reflexionar sobre cuestiones generales relacionadas con la enseñanza.

- Una sección de autoevaluación, que contiene descriptores del tipo «sé»o «puedo hacer», para encauzar la reflexión y la auto-evaluación.

- Un dossier, para evidenciar los resultados de la autoevaluación y registrar ejemplos del trabajo en la enseñanza.

\section{4}

En 2011, el Instituto Cervantes desarrolla un proyecto para definir el perfil de un profesional docente de la institución e involucra en él, además de a representantes

7. <http://www.ecml.at/epostl>.

8. $<$ http://epost12.ecml.at/LinkClick.aspx?fileticket $=$ Odz4pL2JvAk\%3D\&tabid=505\&language $=$ de-DE $>$. 
de muchos de los sectores de trabajadores de la sede central y de centros, a expertos internos y externos y a numerosos estudiantes del Instituto Cervantes de todo el mundo. El desarrollo y los resultados del análisis llevado a cabo se pueden consultar en "QUÉ ES SER UN BUEN PROFESOR O UNA BUENA PROFESORA DEL INSTITUTO CERVANTES».

Se trata de un documento muy importante pues lo allí expuesto trasciende los límites del propio Instituto, dado que, más allá de la especificidad añadida que da la marca de la institución (que a su vez sirve de modelo de actuación para otros muchos entes dedicados a la enseñanza de la lengua), se encuentran los principios considerados útiles y necesarios para definir el perfil docente.

\subsection{Proyecto Epg-European Profiling Grid For Language Teachers $^{10}$}

Cofinanciado por la Comisión Europea, se enmarca en el programa de Aprendizaje Permanente - Lifelong Learning Programme-. El equipo que lleva a cabo el proyecto está compuesto por once instituciones internacionales dirigidas por el CIEP. Se puso en marcha en octubre de 2011, tiene prevista una duración de dos años.

Richard Rossner de EAQUALS, en la Newsletter 01, Febrero 2012. EPG, resume así objetivos y alcance de este proyecto: «El objetivo principal es desarrollar una parrilla de referencia como herramienta útil para evaluar las competencias del profesor de lenguas. En concreto, permitirá que los profesores se autoevalúen y adquieran una visión de conjunto de sus competencias y de sus necesidades de formación. La parrilla será también muy útil para los formadores y los responsables académicos que apoyan el desarrollo profesional de los profesores y optimizan la gestión del personal docente en sus centros de trabajo».

Ahora lo interesante sería que los profesores se habituasen a la consulta y uso de estos documentos sobre el perfil docente no sólo porque marcan o influyen en mayor o menor medida en los diferentes procesos de selección, sino como documentos para poder realizar el seguimiento de la propia evolución profesional.

Es de obligada consulta el taller sobre CDD ofrecido por integrantes del equipo de dirección académica del Instituto Cervantes (Duque, Gil, Juan y Sanz) en el Primer Congreso Mundial de Profesores de Español, COMPROFES, noviembre 2011 (<http://comprofes.es >), en la dirección: <http://comprofes.es/ videocomunicaciones/la-competencia-digital-docente-\%C2\%BFqu $\%$ C3\%A9sabemos-y-qu\%C3\%A9-podemos-hacer $>$.

9. <http://cfp.cervantes.es/recursos/proyectos/default.htm>.

10. $<$ http://www.epg-project.eu $>$. 


\section{Tareas 2.0}

Nos hallamos inmersos en una nueva normalidad de la que no podemos sustraernos puesto que impregna y forma parte sustancial de nuestras vidas en muchos de sus aspectos (profesional, académico, social, etc.). Por lo tanto, nuestro planteamiento como docentes debería partir de la reflexión sobre los tipos de escenarios y tareas que debemos proponer y recrear para apoyar el proceso de aprendizaje de nuestros estudiantes en este escenario en el que las TIC forman parte de manera natural. Dado que han cambiado los canales de comunicación y la forma de obtener información, canalizarla y distribuirla, seremos eficaces en la resolución de problemas en la medida en que conozcamos el potencial de las herramientas a nuestra disposición y las usemos de forma adecuada.

Claramente para que una acción se inscriba dentro de la filosofía de la Web 2.0 no basta que se haga uso de alguna de sus herramientas, sino que es necesario que sea coherente con los principios en los que se apoya la Web 2.0. Es decir, que se dé la posibilidad de generar contenido o publicar contenido, compartirlo con otros y participar en la gran conversación digital. Cabe entonces preguntarse qué tipo de actividades podrían alcanzar la categoría de tareas 2.0, puesto que es muy fácil caer en el error de calcar planteamientos de tipo tradicional de la enseñanza, reduciendo la novedad, exclusivamente, a la introducción de los aspectos propios de la enseñanza con ordenador, sin abrirnos a las posibilidades reales que nos ofrece Internet (de tal modo, se podría hablar de introducción de las TIC en el aula, pero no de su efectiva integración).

Uso de la lengua

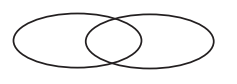

Uso de la Web 2.0

Tareas 2.0

Entre las diferentes posibilidades, rompemos una lanza a favor de la utilización en el aula ELE de WebQuest (en adelante, WQ), también conocidas como EleQuest, pues constituyen un modelo que ha sabido cambiar y adaptarse a los tiempos y a las diferentes novedades que han ido apareciendo en el panorama tanto pedagógico como tecnológico.

Como sabemos, las WQ son una concreción del Enfoque por Tareas en un intento por dar cabida de forma racional a las TIC en el aula de ELE. Se trata, por lo tanto, de otra manera de instruir desde ese enfoque metodológico, sirviéndonos de un modelo coherente, sencillo y rico que se traduce en un protocolo fácilmente asumible y aplicable al aula. De esta manera, podremos participar activamente de la integración de las TIC en el aula de español. Al partir de una 
base teórica y práctica consolidada en el bagaje de los docentes (principios, implicaciones y desarrollo del enfoque comunicativo), no se tiene en ningún momento la sensación de estar dando un salto en el vacío o de moverse por terrenos poco firmes, pues el análisis teórico que respalda las WQ es incuestionable. Además, no olvidemos que nos hallamos ante la estrategia didáctica diseñada especialmente para la Web que ha vivido mayor difusión entre la comunidad educativa desde que existe Internet y esto, sin lugar a dudas, no responde a ninguna moda, sino a un planteamiento riguroso. Las experiencias que podemos encontrar para cualquier asignatura, y obviamente para la enseñanza de una segunda lengua, y para cualquier nivel educativo son innumerables. A priori, la parte técnica que conllevan (elaboración de un documento Web, uso de Internet, búsqueda eficaz de recursos, etc.) podría resultar un escollo para muchos de nosotros que no somos ni mucho menos, nativos digitales. La sustentación teórica hace que el temor quede diluido, y más aún si tenemos en cuenta las facilidades que hallamos en línea (plantillas, guías, generadores de WQ, etc.) a poco que busquemos.

Son muchas las definiciones que podemos encontrar de WQ pero, para partir de los orígenes del modelo, nos remitimos a la que podemos perfilar con los postulados de sus mayores defensores, Bernie Dodge y Tom March. Se trata de una metodología didáctica de aplicación racional de las TIC (concretamente, de Internet) en el aula, basada en el constructivismo y en los principios del aprendizaje cooperativo. En ella, se propone un modelo de uso educativo de los recursos y de su integración en el aula, caracterizado por ser coherente, asequible, sencillo y rico con el que se busca rentabilizar el tiempo de los estudiantes, centrándonos en el uso de la información más que en su búsqueda, y con el que se pretenden reforzar los procesos intelectuales en los niveles de análisis, síntesis y evaluación. Es también un protocolo, dado que se estructura con unas partes fijas y unos convencionalismos, perfectamente reconocibles e identificables por toda la comunidad de usuarios.

Centrándonos en el ámbito concreto que nos interesa, nos remitimos a una definición que ofrecimos ya en 2008 y que consideramos que no ha perdido un ápice de su validez.

Podríamos definir la WQ para ELE como un modelo instructivo de integración de las TIC, que se concreta en actividades de aprendizaje basadas en recursos de la red (aunque no de forma exclusiva) y enmarcadas en un preciso protocolo, cuyo fin es que el alumno - como individuo e integrante de un grupo- mejore su competencia en ELE al realizar una tarea en la que se fomente un alto nivel de implicación cognitiva y suponga una verdadera transformación de la información, promoviendo el uso comunicativo y significativo de la lengua. (Hernández, 2008). 
Cabría ahora preguntarse qué hace de las WQ un modelo a se y per se, si no mejor, sí diferente en algunos puntos, al planteamiento de las unidades didácticas por tareas con o sin la integración de las TIC en su planteamiento y desarrollo. La posible respuesta se halla en los siguientes puntos:

- Se trata de una metodología didáctica de aplicación racional de las TIC en el aula con un modelo y protocolo propio.

- Se aplican, por lo tanto, en ámbitos en los que se busca la integración de las TIC.

- Los recursos en su mayor parte están en la web, aunque no exclusivamente.

- Físicamente las WQ se presentan en forma de documento web.

- El producto suele ser una presentación de tipo multimedia (aunque no exclusivamente).

- Entre las destrezas que se desarrollan se cuentan siempre habilidades técnicas (aunque ese no sea su principal objetivo).

- Y sobre todo, hay que destacar la filosofía que las alimenta apoyada desde siempre por su creador y todos aquellos que le han seguido: permitir a los docentes formar parte de una comunidad. Cada WQ creada debería ponerse a disposición de los docentes que deseen consultarla o usarla en espacios de la red diseñados especialmente para ello.

Pasamos ahora a las características específicas de una WQ para ELE (aunque muchas de ellas, como veremos, pueden resultar muy obvias, no está de más tenerlas presentes para no desvirtuar el verdadero significado de un actividad de este tipo):

1. La finalidad última de la WQ es posibilitar y facilitar el aprendizaje del español.

2. El producto final debe suponer un uso comunicativo y significativo del español y el proceso debe estar orientado a ello. Puesto que nos hallamos en un ambiente de cooperación, se promoverá en lo posible el uso del español en las tareas procedimentales.

3. Se fomenta un uso significativo del español utilizando recursos y materiales auténticos que nos ofrece la red (aunque no se excluye el uso de otros materiales).

4. Presenta un protocolo propio en el que:

+ los recursos se integran en el proceso para facilitar el desarrollo de la actividad.

- la evaluación debe contemplar, entre otras cosas, criterios de aprendizaje relativos a ELE. 
- la guía didáctica se considera un elemento crítico en su composición y, en ella, quedan especificados, entre otras cosas, los objetivos tanto lingüísticos como no lingüísticos que se quieren alcanzar.

5. Se sirve de un andamiaje específico para ELE (sea este del tipo que sea - sintáctico, cultural, etc. y especialmente léxico, dada la lengua de los recursos), sin que esto excluya el recurrir a otros tipos de apoyo si fueran necesarios.

6. Se puede orientar a la práctica específica de cualquiera de las destrezas básicas de la lengua, si bien se pueden integrar varias o todas a lo largo de la actividad. Esto, que se traducirá en un uso significativo del español, debe prevalecer sobre el desarrollo de otras habilidades ya sean estas creativas, sociales o técnicas, aunque también estas se promuevan.

7. Debe estar perfectamente integrada en el currículo de ELE y responder a necesidades específicas de los aprendientes, en un ambiente global de integración coherente y racional de las TIC en el aula.

8. Es decisiva la adecuación al nivel lingüístico de los alumnos tanto de los recursos, como del diseño del proceso y de la tarea. Hay que tener muy en cuenta la competencia del alumno en español para realizar la tarea propuesta.

Es difícil encontrar un ámbito en el que no puedan resultar útiles, pero se revelan de especial validez como base para crear materiales de Español para fines específicos y para el acercamiento a la cultura hispana dado que en la red encontramos gran riqueza de materiales constantemente actualizados y nos será fácil hallar contextos temáticos relevantes.

El modelo de WQ para ELE es aplicable a la práctica de cualquiera de las destrezas básicas de la lengua. Especialmente, comprensión lectora y adquisición léxica dado el amplio contacto con materiales auténticos que se hallan en la red con los que el alumno se encuentra (aunque cada vez más se incluyen también archivos de sonido, lo cual contribuiría al desarrollo de la comprensión auditiva, que por su parte, se activa especialmente al ser expuesto el producto final de la tarea, momento en el que cobra también mucha fuerza la expresión oral y qué decir de la expresión escrita, generalmente presente a lo largo de todo el proceso y en la tarea final). La ventaja está en que cuando llevamos a cabo una WQ también se ponen en acción otras destrezas, no sólo las lingüísticas relacionadas con los procesos de pensamiento y creatividad, sino también otras habilidades sociales, como la cooperación con el grupo y la inmersión en un discurso comunicativo auténtico y, claro está, habilidades técnicas o informáticas (de alfabetización informática o de perfeccionamiento). 
Insistimos sobre una idea que no deberíamos perder de vista: más allá de los criterios que caracterizan estas actividades y desde un punto de vista organizativo o social, podríamos señalar como un elemento no crítico de una WQ de ELE que su autor o autores, de acuerdo con la filosofía que alimenta las WQ en general y que las diferencia de las demás actividades, haga partícipes a los demás docentes de su experiencia poniendo la WQ a disposición de la comunidad. De esta manera, cada WQ diseñada entrará a formar parte de un directorio de WQ/ELE en la red, abierto a las consultas, recepción de comentarios, críticas y/o mejoras por parte de cualquier compañero.

Como afirma Jarvas N. Barato ${ }^{11}$ «El propósito de las WebQuests está relacionado con la filosofía de la web, que es la de dar acceso, libertad y un uso vivo de la información. Las WebQuests son elaboradas por los profesores y publicadas en la web para su uso universal. (...) La filosofía de la web no es la de evaluar como se comercializa una idea, ni cuánto ganaremos con ella. La cuestión es realizar un trabajo abierto dentro de un marco de libertad y cooperación...»

Como ya dijimos en la apertura de este apartado, las WQ han sabido adaptarse y evolucionar con los tiempos (de Web 1.0 a Web 2.0) integrando de forma eficaz nuevas herramientas y proponiendo nuevos usos y modelos siempre en la óptica de mejorar y facilitar el aprendizaje por parte de nuestros alumnos.

A modo de ejemplo incluimos tres WQ, la primera, creada en Web 1.0 y las otras dos perfectamente situadas en la generación colaborativa, de forma que, quien lo desee, las pueda comparar.

1. Mi España, tu España: <http://marcoele.com/descargas/3/hernandezespana.pdf>

2. Aunque la mona se vista de seda: <https://sites.google.com/site/cpascuale/>

3. Coloquémonos. Las colocaciones en el español para fines específicos:

$<$ https://sites.google.com/site/elequestcoloquemonos/>

Cerramos el presente apartado, llamando la atención del lector sobre las VirtualQuest, variante de las WQ en la que queda reflejada perfectamente esa evolución a la que aludíamos y sobre las que nos consta que se está trabajando en la actualidad a nivel universitario. ${ }^{12}$

11. http://webquest.futuro.usp.br/index.html

12. Consideramos que también las Cazas del Tesoro para ELE tienen su espacio entre las posibles Tareas 2.0 pues han seguido una evolución paralela a la de las WQ en cuanto a integración de TIC en su planteamiento y desarrollo. 


\section{Recursos}

En la presente generación, la Web sigue ofreciendo innumerables recursos para la enseñanza de idiomas. Dada la flexibilidad del medio, muchos de ellos se pueden utilizar de manera integrada, adaptándose así a los distintos perfiles y necesidades de los grupos concretos de alumnos.

Según el tipo de recursos, podemos indicar diferentes usos específicos de la Web en la Enseñanza / Aprendizaje de un idioma:

- Fuente de contenidos específicos de la lengua objeto de estudio.

- Fuente de recursos auténticos.

- Fuente de herramientas de comunicación e interacción.

- Fuente de herramientas para la elaboración de materiales.

- Espacio de publicación de materiales por parte de los profesores.

- Espacio de publicación de creaciones de los alumnos (producto de actividades de aprendizaje).

Es el profesor quien decidirá, según las características de sus alumnos y el contexto, qué integrar en el aula y cómo hacerlo. Las variables que inciden en la modalidad son numerosas: las necesidades del currículo, el perfil de los estudiantes, el equipamiento, etc. Ciñéndonos al tema de los recursos, el problema hace tiempo que no radica en contar con una cantidad suficiente de ellos, sino en saber discriminar entre cantidad de posibilidades que se nos ofrecen a través de la Web.

Dado que el perfil de «fuente de input» de la Web 2.0 no ha cambiado (se ha incrementado si cabe), queremos indicar una serie de recursos Web que consideramos esenciales para cualquier docente o futuro docente de ELE. No es nuestra intención ser exhaustivos; para esto ya existen publicaciones específicamente dedicadas a ello. Además, a la hora de hablar de recursos debemos tener presente la breve vida que pueden tener muchos de los que se recogen en diferentes recopilaciones, precisamente por el carácter cambiante y el continúo movimiento de la red.

- FORMESPA (lista y espacio de colaboración): <http://formespa.rediris.es/>

- TODOELE (página del profesor y comunidad): <http://www.todoele. net/>

- Instituto Cervantes (CVC: enseñanza / lengua): < http://cvc.cervantes.es/portada.htm>

- REDELE (biblioteca y revista): <http://www.educacion.gob.es/redele>

- MARCOELE (revista, suplementos, monografías y actividades): $<$ http://marcoele.com/>

- L De Lengua (podcast para profesores): <http://eledelengua.com/> 


\section{Conclusiones y desarrollo futuro}

Como ya hemos dicho, la dimensión digital ha provocado y está provocando cambios no sólo en nuestra cotidianeidad, sino también en todo lo que forma parte de nuestro mundo, incluida la enseñanza y el aprendizaje. Es necesaria una buena dosis de reflexión, de objetividad y de valoración de todas las posibilidades que se nos brindan, anteponiendo, como afirman Herrera y Conejo (2009), siempre las actitudes y enfoques pedagógicos al mero despliegue de herramientas y servicios Web.

La tecnología debe estar siempre incluida en situaciones de enseñanza y aprendizaje, con un diseño adecuado dentro del marco instructivo y con unas estrategias claras de evaluación.

Cuando estas herramientas educativas provoquen en nuestros alumnos desconcentración, confusión, frustación o la reacción sea de desinterés, obviamente, no se está haciendo un uso pertinente y adecuado de las mismas. Tendremos entonces que optar por un replanteamiento para ir valorando y mejorando su integración en nuestra realidad educativa de la forma y en el momento que sea más oportuno.

Cuando, en cambio, las TIC promuevan un aprendizaje significativo, activo y basado en la experiencia, constructivo, colaborativo y autónomo significará que se está haciendo un uso adecuado y eficaz de las posibilidades que nos brindan. Escogeremos, entre todas, la tecnología que mejor se adapte al objetivo final que queremos conseguir sin perder de vista que para que una acción se inscriba dentro de la filosofía Web 2.0 no basta con realizarla empleando alguna de sus herramientas, sino que es fundamental que sea también coherente con los principios en los que se apoya la Web 2.0.

... si el uso de Internet en el aula carece de la didactización adecuada, puede resultar frustrante y generar ansiedad. Por lo tanto, es necesario analizar su potencial como posibles herramientas pedagógicas y aplicar una metodología acorde con su uso en el aula. De nada sirve repetir antiguos modelos de enseñanza pero con una presentación diferente porque la interacción, la colaboración y la construcción colectiva de conocimiento no existirían. (Yagüe 2007:34)

Lo cierto es que la sinapsis entre aprendizaje y red social está dando lugar a una gran ebullición de ideas; está claro que estamos en una sociedad en cambio constante y, por lo tanto, para ir con los tiempos, tenemos que mantener abierta nuestra concepción del aprendizaje y estar dispuestos a una gran flexibilidad.

Tal como observa Olga Juan (1999:1), «lo que necesitamos los profesores son materiales a través de los cuales, primero, podamos observar que nuestros 
estudiantes obtienen resultados en su aprendizaje y, segundo, haya un análisis teórico detrás que permita seguir indagando y avanzando en el aprendizaje de las lenguas».

En conclusión, la reflexión, la objetividad, la capacidad de valorar adecuadamente todas las posibilidades y una buena dosis de sentido crítico deberían ser los principios que guiasen siempre nuestra actuación en este campo que cada día nos ofrece cambios y novedades.

\section{Referencias bibliográficas}

Adell, J. (2007). «El tratamiento de la información y competencia digital». En: IV Congreso Regional de Educación de Cantabria. Competencias Básicas. [Disponible en: <http //www.youtube.com/watch?v=Ri_S7_a12y0>].

Adell, J. La competencia digital. [Disponible en: <http://www.youtube.com/ watch?v=tjC1LOC0r1g $>$ ].

- Blog Edu E Tec. [Disponible en: <http://elbonia.cent.uji.es/jordi/>]

- (2007). «Wikis en educación». Enः Cabero, J. y Barroso, J. (Eds.). Posibilidades de la teleformación en el espacio europeo de educación superior. Octaedro, Andalucía, pp. 323-333. [Disponible en: <http //www.dinstitucio. $\operatorname{org} / 20 />$ ].

Aguaded, J. I. (2002). «Internet, una red para la información, la comunicación y la educación». En: Aguaded, J. I. y Cabero, J. (Eds.). Internet como recurso para la educación. Málaga. Aljibe: 17-56.

Alexander, B. (2006). "Web 2.0. A New Wave of Innovation for Teaching and Learning?». Educause Review. Marzo/abril. Volumen 41-2: 33-44. [Disponible en <http://www.educause.edu/ir/library/pdf/ERM0621.pdf> ].

Alonso Fernández, A (2012). Los blogs en la enseñanza del español como lengua extranjera. Tesina de máster: Tecnologías para la educación y el conocimiento UNED. Marcoele. N. 14. [Disponible en: <http //marcoele.com/suplementos/los-blogs-en-la-clase-de-ele/> ].

Anderson, P. (2007). «What is Web 2.0? Ideas, technologies and implications for education». En: JISC, Technology and Standards Watch, 07. [Disponible en: <http://www.jisc.ac.uk/media/documents/techwatch/tsw0701b.pdf> ].

Area, M. (2011). «Educar para la cultura líquida de la Web 2.0ः Apuntes para un modelo de alfabetización digital». En: I Congreso Internacional sobre Educación Mediática y Competencia Digital. Segovia. [Disponible en: <http://www. 
educacionmediatica.es/comunicaciones/Eje\%204/Manuel\%20Area\%20 Moreira.pdf $>$ ].

Arrarte, G. (2011). Las tecnologías de la información en la enseñanza del español. Manuales de formación de profesores de español 2/L. Arco Libros.

Arrarte, G. y Sánchez de Villapadierna, J.I. (2001). Internet y la enseñanza del español. Madrid. Arco/Libros - Cuadernos de Didáctica del español/LE.

Benito Gómez, M. (2008). «Educar en comunidad: tendencias educativas en el nuevo entorno digital». Revista BIT. n. ${ }^{\circ} 167: 37-45$.

Bermejo, I. e Higueras, M. (2000). «Recursos en Internet para la comprensión lectora: actividades, obras en línea, listas de distribución, bibliografía y otros recursos de Internet». La comprensión lectora en el aula de ELE. Carabela 48: 141-149.

Blanco, S. (2005). «Los weblogs como herramienta didáctica en el seno de una asignatura curricular». En: López García G. (ed.). El ecosistema digital: modelos de comunicación, nuevos medios y público en Internet. Valencia. Servei de Publicacions de la Universitat de València: 151-166.

Bordoy Verchili, M. (1999). «Listas de distribución en la Internet: puentes hacia la cooperación internacional». Mosaico. 2: 20-21.

Boulos, M. N. K. et alii (2006). «Wikis, blogs and podcasts: a new generation of web-based tools for virtual collaborative clinical practice and education». BMC Medical Education. Vol. 6-41. [Disponible en: <http://www.biomedcentral.com/1472-6920/6/41>].

Brittain, S. et alii (2006). «Podcasting Lectures. Formative evaluation strategies helped identify a solution to a learning dilemma».Educause Quartely. Vol. 29-3. [Disponible en <http://www.educause.edu/ir/library/pdf/eqm0634. $\operatorname{pdf}>$ ].

Burgess, J. (2006). «Blogging to Learn, Learning to Blog». En: Bruns, A. \& Jacobs, J. (eds.). Uses of Blogs. New York. Peter Lang: 105-114.

Campbell, A. (2003). «Weblogs for Use with ESL Classes». The Internet TESL Journal. 9-2. Febrero. [Disponible en: <http://iteslj.org/Techniques/Campbell-Weblogs.html>].

Campbell, G. (2005). «There's Something in the Air: Podcasting in Education». EDUCAUSE Review. Vol. 40. Núm. 6: 32-47. [Disponible en: <http:// www.educause.edu/apps/er/erm05/>]. 
Cassany, D. (2004). «Usando el Portfolio Europeo de las Lenguas (PEL) en el aula». Mosaico. Vol. 9. [Disponible en: <http //www.sgci.mec.es/be/media/ pdfs/articulos/Mosaico09_2.pdf $>$ ]

Carrillo, C.M \& Pentikousis, K. (2008). «An Application of wikis for mediated collaborative learning to Spanish L2». [Disponible en: <http://ipv6. willab.fi/kostas/>].

[COMprofeS] Congreso Mundial de Profesores de Español. [Disponible en: <http://comprofes.es $>$ ].

Concheiro, P. (2011). «Aplicación de nuevas tecnologías en el aula deELE. Presentación de un caso práctico: los blogs de grupo como herramienta de aprendizaje colaborativo». En: IV Congreso Internacional de FIAPEः La enseñanza del español en un mundo intercultural. Jornadas pedagógicas. Facultad de Filología de la Universidad de Santiago de Compostela. 17-20.04.2011. [Disponible en <http://folk.uio.no/jmaria/pruebas/Concheiro.docx $>$ ].

Consejo de Europa (2002). Marco Común Europeo de Referencia para las lenguas: aprendizaje, enseñanza, evaluación (MCER). [Disponible en: <http:// cvc.cervantes,es/obref/marco $>$ ].

Cruz Piñol, M. (1999). «Espan-L, un "foro de debate" en la Internet sobre la lengua española». Estudios de Lingüística Española. vol. 1. [Disponible en: <http://elies,rediris,es/elies1/>].

- (2001). «Webs para la enseñanza del ELE. El reto de encontrar el material adecuado para cada situación». Es Espasa. Revista de profesores.

- (2001). «Recursos en Internet para la elaboración de actividades». Sección fija de la revista Carabela. [Disponible en: <http://www.ub.es/filhis/culturele/ carabela.html> ].

- (2002). Enseñar español en la era de Internet. La WWW y la enseñanza del español como lengua extranjera. Barcelona. Octaedro. [Disponible en: <http:// www.octaedro.com/ele/> ].

- (2004). «Presencia (y ausencia) de los 'hipermedios' y de los 'géneros electrónicos' en las Webs para la enseñanza-aprendizaje del español como lengua extranjera (ELE)». Cultura y Educación. 15(3): 311-325; y en RedELE. [Disponible en: <http://www.mec.es/redele/revista/cruz_pinol.shtml> ].

Cruz Piñol, M.; Duque De la Torre, A.; Ginés Surià, I,; y Sitman, R. (1999). «Tareas virtuales. ¿Es oro todo lo que reluce en la Internet?». En: Español como lengua extranjera: enfoque comunicativo y gramática. Actas del IX Congreso de ASELE. Universidad de Santiago de Compostela: 743-751. 
Chenoll Mora, A. (2009). «La web 2.0 una ventana abierta a la interculturalidad». En: Fernández Colomer, Ma José y Albelda Marco, Marta. Foro de Profesores de E/LE. V. [Disponible en* <http*//www.uv.es/foroele/foro5/ Chenoll.pdf $>$ ].

De Basterrechea, J. P. y Juan Lázaro, O. (2005). «Influencia de los recursos digitales y los sistemas de comunicación en el modelo de enseñanza de ELE». En: Actas del Primer Congreso Internacional de FIAPE, Federación Internacional de Asociaciones de Profesores de Español. [Disponible en: <www.sgci.mec. es/redele/biblioteca2005/fiape.shtml> ].

De Ugarte, D. (2006). El poder de las redes. Manual ilustrado para personas, colectivos y empresas abocados al ciberactivismo. [Disponible en: <http://www. deugarte.com/gomi/el_poder_de_las_redes.pdf $>$ ].

Del Moral, M. (2007). «Una herramienta emergente de la Web 2.0ः la wiki. Reflexión sobre sus usos educativos». Unión: revista iberoamericana de educación matemática. N.o 9: 73-82. [Disponible en: <http‡//www.fisem.org/ paginas $>$ ].

Duque de la Torre, A.; Gil Bürman, M.; Juan Lázaro, O.; Sanz de la MoRENA, C. (2011). «La competencia digital docenteः ¿qué sabemos y qué podemos hacer?». En: Congreso mundial de profesores de español, Instituto Cervantes. Unidad TIC aplicadas a ELE. [Disponible en: <http*// comprofes.es/videocomunicaciones/la-competencia-digital-docente-\%C2\%BFqu\%C3\%A9-sabemos-y-qu\%C3\%A9-podemos-hacer $>$ ].

EAQUALS: A Profiling Grid for Language Teachers. V.3.0. [Disponible en: $<$ http://clients.squareeye.net/uploads/eaquals/North-\%20TQAC.pdf>].

Echeverría, J. (1999). Los Señores del aire: Telépolis y el Tercer Entorno. Barcelona. Destino.

Ellis, R. (2003). Task-based Language Learning and Teaching. Oxford. OUP.

Erdocia IÑiguez, I. (2012). «El aprendizaje autónomo a través de las redes sociales. Experiencia práctica». En: III Encuentros virtuales Comunidad Todoele. [Disponible en: <https $/ /$ webconf.vc.dfn.de/p38mcts $8 \mathrm{cx} 5 /$ ?launcher $=$ false $\& \mathrm{fcs}$ Content $=$ true $\& \mathrm{pbMode}=$ normal $>$ ].

- (2012). «El aprendizaje autónomo a través de las redes sociales (Memoria de Master)». RedELE, Biblioteca 2012. Ministerio de Educación y Ciencia. [Disponible en: <http://www.educacion.gob.es/redele/Biblioteca-Virtual/2012/memoria_Master/Iker-Erdocia.html > ]. 
Esteve J. M. (2003). La tercera revolución educativa. La educación en la sociedad del conocimiento. Barcelona. Paidós.

Fernández-Pinto, J. (2000). «Guía para usar Internet en clase». DidactiRed. [Disponible en: <> http $\$ / /$ cvc.cervantes.es/aula/didactired/anteriores/diciembre_00/29122000.htm >].

Freedman, T. (ed.). (2006). Coming of Age. An Introduction to The New World Wide Web. [Disponible en: http://www.ictineducation.org].

Fundación Teléfonica (2011). Las TIC en la Educación. Realidad y expectativas. Informe anual 2011. [Disponible en: <http://www.fundacion.telefonica. com/es/debateyconocimiento/media/publicaciones/TIC_educacion.pdf $>$ ].

García, F. (2005). «El papel de los portafolios electrónicos en la enseñanza-aprendizaje de las lenguas». Glosas Didácticas. Vol. 14. Universidad de Murcia. [Disponible en: <http //www.um.es/glosasdidacticas/GD14/completo.pdf > ] .

García PÁez, F. (2007). «Estrategias didácticas para trabajar la competencia digital». IV Congreso Regional de Educación de Cantabria. Competencias básicas y práctica educativa. [Disponible en: <http://www.youtube.com/ watch?v=Ri_S7_a12y0>].

García-Valcárcel, A. (2003). Tecnología educativa. Implicaciones educativas del desarrollo tecnológico. Madrid. La Muralla.

Gelado, J. A. (2006). «De los blogs al podcasting. ¿Continuidad o disrupción?» La blogosfera hispana. Pioneros de la cultura digital. Fundación France Telecom. [Disponible en: <http://www.fundacionauna.com/areas/25_publicaciones/ la_blogosfera_hispana.pdf $>$ ].

Gisbert Cervera, M. (2002). «El nuevo rol del profesor en entornos tecnológicos». Acción Pedagógica. Vol.11. Núm. 1: 48-59. [Disponible en: <http:// dialnet.unirioja.es/servlet/articulo y en http://www.saber.ula.ve/handle/123456789/4113>].

Gisbert, C. M; Adell, J., Rallo, R. y Bellver, A. (1998). «Entornos virtuales de enseñanza-aprendizaje». Cuadernos de Documentación Multimedia. [Disponible en: <http://www.ucm.es/info/multidoc/multidoc/revista > ].

González, M. «El podcast, su uso didáctico, idiomas e interculturalidad». Cuaderno Intercultural. [Disponible en: <http://www.cuadernointercultural. $\mathrm{com} /$ tic-tools/herramientas-2-0/>].

Grupo Nodos ELE (2007). Manifiesto constructivista. [Disponible en: <http:// www.nodosele.com/blog/2007/08/31/nuestro-ideario/> ] 
- (2009). Manifiesto conectivista. [Disponible en: <http://www.nodosele. com/?page_id=2>].

Hernández Mercedes, M. P. (2007). «Recursos para la integración de las TIC en el aula ELEः Cazas del Tesoro». En: XV Encuentro Práctico de profesores de ELE. 16-17 diciembre 2006. Barcelona. IH / Difusión. [Disponible en: $<$ http://www.encuentro-practico.com/pdf06/hernandezp.pdf $>$ ].

- (2007). «Aula de español, enfoque por tareas y TIC. Algunas reflexiones sobre las WebQuests en el aula de ELE». Revista digital de didáctica MarcoELE. Núm. 5. Julio-diciembre 2007. [Disponible en: <http://www.marcoele.com/ num/5/index.html $>$ ].

- (2008). «Tareas significativas y recursos en Internet: WebQuest». Revista digital de didáctica MarcoELE. Núm. 6. Enero-junio 2008. [Disponible en: <http://www.marcoele.com/num/6/02e3c09a600997f04/pilarh.pdf> ].

Hernández Requena, S. (2008). «El modelo constructivista con las nuevas tecnologías: aplicado en el proceso de aprendizaje». Comunicación y construcción del conocimiento en el nuevo espacio tecnológico [monográfico en línea]. Revista de la Universidad y Sociedad del Conocimiento (RUSC). Vol. 5, número 2. UOC. [Disponible en: <http://www.uoc.edu/rusc/5/2/dt/esp/ hernandez.pdf $>$ ].

Herrera, F. (2007). «Web 2.0 y didáctica de lenguas: un punto de encuentro». Glosas didácticas. 16: 18-26. [Disponible en: <http://www.um.es/glosasdidacticas/gd16/02herrera.pdf $>$ ].

- (2011). «Aprendizaje en red y actividades digitales significativas». Mosaico. Revista para la promoción y Apoyo a la Enseñanza del Español. Núm. 28. Consejería de Educación en Bélgica, Países Bajos y Luxemburgo. [Disponible en: $<$ http: //franherrera.com/almacen/franherrera-mosaico-28.pdf> ].

- Blog sobre la adquisición de segundas lenguas y la web colaborativa. [Disponible en: <http //lajanda.blogspot.com/ Desde 2011 en: http://franherrera. $\mathrm{com} />$ ].

Herrera, F. y Conejo, E. (2009). «Tareas 2.0: la dimensión digital en el aula de español lengua extranjera». MarcoELE. 9: 1-20. [Disponible en: <http:// marcoele.com/tareas-2-0-la-dimension-digital-en-el-aula-de-espanol-lengua-extranjera/ $>$ ].

Higueras García, M. (2002). «Cómo elaborar material para Internet para la enseñanza del español con fines específicos». En: Actas del I Congreso Internacional de Español para Fines Especificos (CIEFE): 75-85. [Disponible en: $<$ http://www.ciefe.com/paginas/pdf/cf1-p-elabmaterialint.pdf $>$ ]. 
- (2004). «Internet en la enseñanza del español». En: Sánchez Lobato, A. y Santos Gargallo, I. (eds.). Vademécum para la formación de profesores. Enseñar español como segunda lengua (L2) / lengua extranjera (LE) Madrid. SGEL: 1061-1085.

Hita Barrenechea, G. (2001). La enseñanza comunicativa de idiomas en Internet: Características de los materiales y propuestas didácticas. Memoria de máster. Madrid. Universidad Antonio de Nebrija.

ISTE (2007). The ISTE NETS and Performance Indicators for Students (NETS ·S). [Disponible en: <http://www.iste.org/standards/nets-for-students.aspx $>$ ]. [En español en: <http://www.eduteka.org/modulos/11/335/59/1>].

Johnson, A. (2004). «Creating a Writing Course Utilizing Class and Student Blogs». The Internet TESL Journal: 10-8. [Disponible en: <http://iteslj.org/ Techniques/Johnson-Blogs $>/$ ]

Jorrín, et alii (2007). «Lo que el ojo no ve: Un estudio de caso basado en procesos de indagación co(wiki)laborativos». RIED: Revista Iberoamericana de Educación a Distancia. Vol. 10. Núm. 2. [Disponible en: <http://www.utpl. edu.ec/ried/index.php >].

Juan Lázaro, O. (2001). Uso de Internet en el aula. Madrid. Edelsa.

- (2006). «¿Enseñanza de español "sin" Internet?». Enciclopedia del español en el mundo. Instituto Cervantes. Círculo de lectores. Plaza\&Janés: 359-363. [Disponible en: <http://cvc.cervantes.es/lengua/anuario/anuario_06-07/pdf/ ele_03.pdf $>$ ].

- (2009). «La autonomía y el fomento de la responsabilidad del estudiante: Los materiales didácticos digitales e Internet en el aula». En: PASTOR, C. (coord.). Actas del programa de formación para profesorado de ELE 2008. Instituto Cervantes. Berlín.

- (2010). «Redes sociales, Web 2.0 y el español: estrategias y recursos». Anotaciones en torno a la conferencia en el XVIII Encuentro Práctico. Barcelona. [Disponible en: <http://www.encuentro-practico.com/pdf09/juan-web.pdf > ].

- (2010). «Las TIC en el aula de español: la competencia digital y la autonomía del estudiante». Mosaico. Revista para la promoción y Apoyo a la Enseñanza del Español. Núm. 25. Consejería de Educación en Bélgica, Países Bajos y Luxemburgo. [Disponible en: <https://sede.educacion.gob.es/publiventa/ detalle.action?cod $=13645>$ ]. 
Juan Lázaro, O. y Fernández Pinto, J. (2000). «Criterios de evaluación de materiales en la red: alumnos y usuarios de ELE». Cuadernos Cervantes de la lengua española. Espacio multimedia. Núm. 28: 70-85.

Kelly, M. et alii (2004). European Profile for Language Teacher Education. A Frame of Reference. University of Southampton. [Disponible en: <http:// ec.europa.eu/education/policies/lang/doc/profile_en.pdf >].

Klenowski, V. (2005). Desarrollo de portafolios para el aprendizaje y la evaluación. Madrid. Narcea.

Lara, T. (2005). «Blogs para educar. Usos de los blogs en una pedagogía constructivista». Telos. Octubre/diciembre. Vol. 65. [Disponible en: <http:// www.campusred.net/telos/articulocuaderno.asp?idarticulo=28 rev=65>].

Le Roy, H. (2000). «Una página web, un instrumento al alcance de todos los profesores de español». Mosaico. 4: 16-20.

Llano, J.; Ainciburu, C. y Juan, O. (2011). «La enseñanza de español a través de videoconferencias de escritorio. Integración en las diferentes modalidades de aprendizaje y desarrollo de competencias». Cuadernos Comillas. 2: 51 68. [Disponible en: <http://www.cuadernoscomillas.es/pdf/ccom2/4_videoconferencia_llano_ainciburu_juan_revision51-68.pdf $>$ ].

Llisterri, J. (1999). «La web en la enseñanza y en el aprendizaje del español como lengua extranjera». [Disponible en: <http://liceu.uab.es/ joaquim/ applied_linguistics/PNTIC_IC_99/PNTIC_IC_99.html>].

- (2001). «Internet y enseñanza de español como lengua extranjera. Referencias». [Disponible en: <http://liceu.uab.es/ joaquim/teaching/Applied_ linguistics/New_Technologies/ELE_Internet_Bib.html >].

Llopis García, R. (2009). «Cultura y web 2.0ः Prensa, foros y debates». En: Fernández Colomer, M. ${ }^{a}$ José y Albelda Marco, Marta (coords.). Foro de Profesores de E/LE. V. [Disponible en: <http://www.uv.es/foroele/foro5/ Llopis_Garcia.pdf $>$ ].

Marquès, P. (1999). «Criterios para la clasificación y evaluación de espacios web de interés educativo». Revista EDUCAR. 25: 95-111. [Disponible en: $<$ http://www.educando.edu.do/sitios/PNC2005/recursos/documentos/ evaluacion\%20pagina\%20web/evaluacion\%20web.htm >].

Méndez Santos, M. C. (2011). «El blog como herramienta docente en la enseñanza-aprendizaje de ELE: de la teoría a la práctica». RedELE, Núm. 23. [Disponible en: <http://www.educacion.gob.es/dctm/redele/Material-Re- 
dEle/Revista/2011_23/2011_redELE_23_13M\%C3\%A9ndez\%20Santos. pdf?documentId=0901e72b8101e78f $>$ ].

Millán, J.A. (2001). Internet y el Español. Madrid. Fundación Retevisión.

Mir, B. (2009). «La competencia digital, competencia metodológica». En: Competencias digitales: conocimientos, habilidades y actitudes para la Sociedad Red. [Disponible en: <http://www.xtec.cat/ bmir/competenciasdigitales/>].

Monereo i Font, C. (2005). Internet y competencias básicas: aprender a colaborar, a comunicarse, a participar, a aprender. Barcelona. Graó.

Newby, D. et alii (2010). PEFPI. Portfolio Europeo para futuros profesores de idiomas. Una herramienta de reflexión para la formación de profesores. Centro europeo de lenguas modernas (CELM) / Consejo de Europa. Ministerio de Educación. Gobierno de España (trad.). [Disponible en: <http://epostl2.

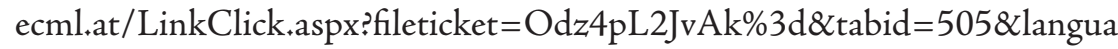
$\mathrm{ge}=\mathrm{en}-\mathrm{GB}>$ ].

Nomdedeu, A (2008). «Actualización de los recursos del docente de ELE en Internet». RedELE. Núm. 12. [Disponible enः <http://www.educacion.gob.es/dctm/redele/Material-RedEle/Revista/2008_12/2008_ redELE_12_06Nomdedeu.pdf?documentId=0901e72b80de14e5> ].

Orihuela, J. L. et alii (2005). Blogs. La conversación en Internet que está revolucionando medios, empresas y a ciudadanos. Madrid. ESIC Editorial.

Owen, M. et alii (2006). «Social software and learning». Futurelab. [Disponible en: <http://www.futurelab.org.uk/download/pdfs/research/opening_education/Social_Software_report.pdf $>$ ].

PEÑA, I. et alii (2006). «El profesor 2.0* docencia e investigación desde la Red». UocPapers, revista sobre la sociedad del conocimiento. 3. [Disponible en: $<$ http://www.uoc,edu/uocpapers $>$ ].

Pérez Torres, I. (2003). «Diseño de actividades de investigación orientada en la web y su Integración en el proceso de enseñanza de lenguas». Enः LúQUE Agullo, G.; Bueno González, A. y Tejada Molina, G. (eds.). Las lenguas en un mundo global /Languages in a global World. Jaén. Servicio de publicaciones de la Universidad. 337. [Disponible en: <http://www.freewebs.

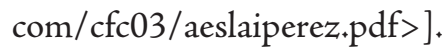

Pérez Torres, I. (2006). «Diseño de Webquests para la Enseñanza / Aprendizaje del Inglés como Lengua Extranjera: Aplicaciones en la Adquisición de Vocabulario y la Destreza Lectora». Granada. Editorial Universidad de Granada. [Disponible en: <http://adrastea,ugr.es/search*spi/aperez+torres/ 
aperez+torres $/ 1 \% 2 \mathrm{C} 3 \% 2 \mathrm{C} 8 \% 2 \mathrm{CB} /$ frameset $\& \mathrm{FF}=$ apere $z+$ torres + maria $+\mathrm{i}$ sabel $\& 1 \% 2 \mathrm{C} 1 \% 2 \mathrm{C}>$ ].

Pujola, J. T. (2006). «La reflexión en el proceso de formación‡ el portafolio». XV Encuentro práctico de profesores de ELE. Barcelona. International House / Editorial Difusión.

Richardson, W. (2006). Blogs, Wikis, Podcasts and Other Powerful Web Tools for Classrooms. California, USA. Corwin Press. Thousand Oaks.

Rodríguez Martín, J. R. (2004). «El uso de Internet en el aula de ELE». RedELE. Núm. 2. octubre 2004. Ministerio de Educación y Ciencia. [Disponible en: <http://www.mec.es/redele/revista2/rodriguez.shtml > ].

Salinas, J.; Cabreno, J. y Aguaded, J. I. (coords.). (2004). Tecnologías para la educación. Diseño, producción y evaluación de medios para la formación docente. Madrid. Alianza.

Siemens, G. (2006). Knowing knowledge. En: elearnspace.com [Disponible en: $<$ http://www.elearnspace.org/KnowingKnowledge_LowRes.pdf $>$ ]. Edición de Nodos Ele: <http://www.nodosele.com/editorial/2010/01/prsentacion/ $>$.

Simons, M. (2010). «Perspectiva didáctica sobre el uso de las TIC en clase de ELE”. MarcoEle. Núm. 11. [Disponible en: <http://marcoele.com/descargas/11/simons-tic.pdf $>$ ].

Sitman, R. (1998). «Divagaciones de una internauta. Algunas reflexiones sobre el uso y abuso de la Internet en la enseñanza del ELE». Boletín de ASELE. 12: 7-33; y en Espéculo. 10. [Disponible en: <http://www.ucm.es/info/especulo/numero10/sitman.html > ].

- (2000). «Espan-L: Lista de distribución para profesores de español como lengua extranjera». En: Cultura e intercultura en la enseñanza del español como lengua extranjera. -Contextos culturales hispánicos en los medios de comunicación $y$ en las nuevas tecnologías. [Disponible en: <http://www.ucm.es/info/especulo/ele/espan_l.html>].

Soria Pastor, I. (2002). «Las nuevas tecnologías en la formación de profesores de ELE». En: Gimeno, A. M* (ed.). Tecnologías de la información y de las comunicaciones en la enseñanza del ELE. Actas del XII Congreso Internacional de ASELE. Valencia. Editorial de la Universidad Politécnica de Valencia:.421-429.

Stanley, G. (2006). Blogs, wikis and podcasts (and Second Life). [Disponible en: $<$ http://blog-efl.blogspot.com/2006_11_01_archive.html>]. 
Tallei, J. (2009). «Las plataformas virtuales en la clase de español (I)». Didactired. 26 octubre 2009. Centro Virtual Cervantes. Instituto Cervantes. [Disponible en: <http://cvc.cervantes.es/aula/didactired/anteriores/octubre_09/26102009.htm >].

- (2010). «Aula Virtual de Español (AVE) y Moodle». Didactired. 21 junio 2010. Centro Virtual Cervantes. Instituto Cervantes. [Disponible en: $<$ http://cvc.cervantes.es/aula/didactired/anteriores/junio_10/21062010. $\mathrm{htm}>$ ].

— (2011). «Las wikis en la enseñanza de ELE». Didactired. 17 enero 2011. Centro Virtual Cervantes. Instituto Cervantes. [Disponible en: <http://cvc.cervantes.es/aula/didactired/anteriores/enero_11/17012011.htm>].

Torres Ríos, L. (2007). «La influencia de los blogs en el mundo de ELE». Glosas didácticas. 17: 1576-7809.

UNESCO (2008). Estándares de competencia en TIC para docentes. [Disponible en: <http://cst.unescoci.org/sites/projects/cst/The\%20Standards $\% 20$ $\mathrm{SP} /$ Forms/AllItems.aspx y http://www.eduteka.org/EstandaresDocentesUnesco.php >].

Valero, A. La experiencia del blog en el aula. [Disponible en: <http://www.consejogeneralcdl.es/materiales_almagro_10/documento\%202.pdf>].

Villatoro, J. (2010). «La competencia digital docente en la enseñanza y aprendizaje de idiomas». En: I Encuentros virtuales Comunidad Todoele. [Disponible en: <http://webconf.vc.dfn.de/p50445507/>].

White, D. \& Le Cornu, A. (2011). «Visitors and Residents: A new typology for online engagement». First Monday. Volume 16. Number 9-5. [Disponible en: <http://firstmonday.org/htbin/cgiwrap/bin/ojs/index.php/fm/article/ viewArticle/3171/3049>].

YAGÜE, A. (2007). «La tostadora se ha vuelto asesina y el ordenador no me puede ver. A propósito de la Internet y la enseñanza del ELE». Glosas didácticas. 16: 1-16. [Disponible en: <http://www.um.es/glosasdidacticas/gd16/01yague. pdf $>$ ].

Zabalza, M. A. (2004). Diarios de clase. Un instrumento de investigación y desarrollo profesional. Madrid. Narcea.

Última consulta direcciones web: 3 de junio de 2012.

Dirección materiales del presente artículo: <http://eneletic2012.wikispaces.com/> 